\title{
An Extraordinary Case of Pheochromocytoma with Breast Cancer in a Patient with Neurofibromatosis Type 1
}

\author{
Jin Woo Jeong ${ }^{1}$, Sunil Jeon ${ }^{1}$, Tae Yang Yu'**, Hun Soo Kim ${ }^{2}$, and Chung Gu Cho ${ }^{1}$ \\ ${ }^{1}$ Division of Endocrinology and Metabolism, Department of Internal Medicine, ${ }^{2}$ Department of Pathology, Wonkwang University School \\ of Medicine, Iksan, Korea
}

A 44-year-old woman was admitted to the hospital for palpitations and sweating. The day before, she underwent a hysterectomy for uterine myoma. Her initial blood pressure was 180/100 mmHg and her pulse rate was 170 beats/ min. She had been diagnosed with hypertension 3 months previously. We noticed multiple café au lait spots, tiny nodules on the back, and skinfold freckling in the axillary and inguinal area (Fig. 1A, B). She had a solid mass in the right breast (Fig. 1B). She also had Lisch nodules on the anterior
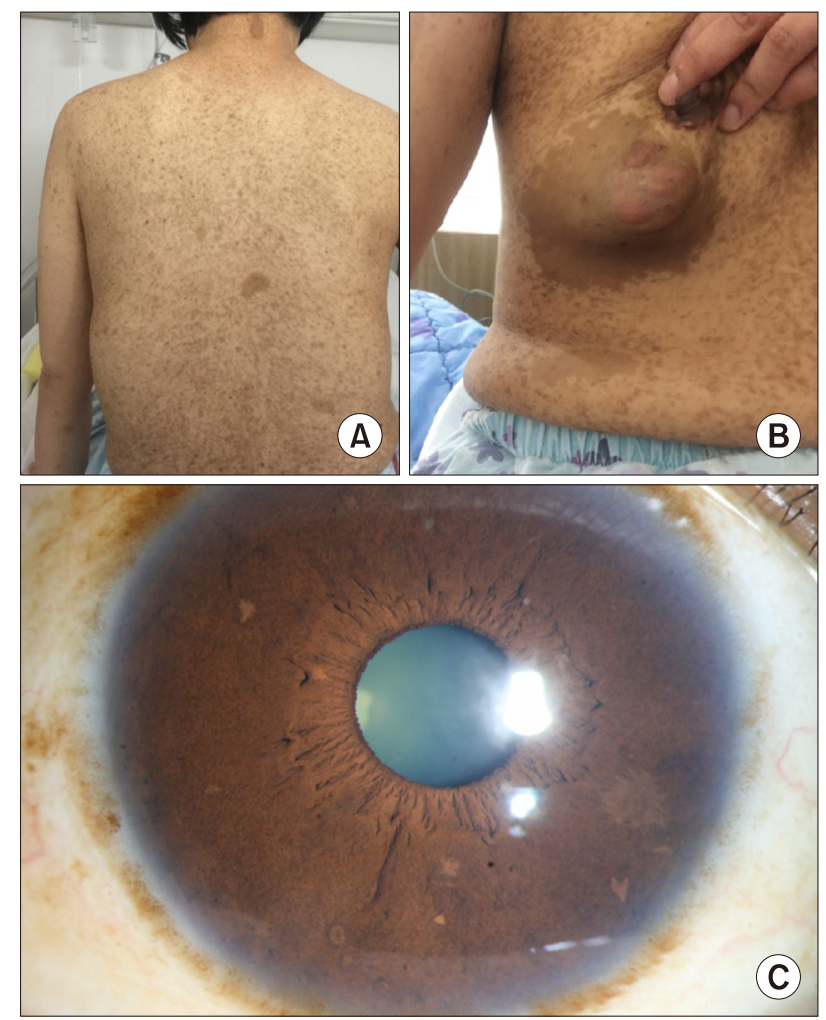

FiG. 1. (A) Multiple café au lait spots and brownish small nodules all over the body. (B) Right breast solid mass with freckling in the axillary area. (C) Multiple small hamartoma lesions in the iris. surface of the iris (Fig. 1C). Her serum metanephrine level was $70.4 \mathrm{nmol} / \mathrm{L}$ and her normetanephrine level was 8.35 $\mathrm{nmol} / \mathrm{L}$. Her 24-hour urinary metanephrine was $28.78 \mathrm{mg} /$ day, and her 24-hour urinary vanillylmandelic acid level was $42.7 \mathrm{mg} /$ day.

Abdominal computed tomography scan showed an ovalshaped, well-defined mass measuring $6 \mathrm{~cm}$ in the right adrenal gland (Fig. 2A). The early diagnosis was pheochromocytoma with neurofibromatosis (NF). We ultrasonographically examined the breast mass. Coincidently, an irregularly spiculated low echoic mass was detected in the left breast (Fig. 2B). Biopsy confirmed NF type 1 (NF1; in the right breast and skin) and invasive breast carcinoma (T1N0M0; in the left breast) (Fig. 2C, D). Right adrenalectomy and left breast-conserving surgery were performed (Fig. 2E).

NF1 is an autosomal dominant disorder reported to occur in 1 in 1,900-3,500 people. ${ }^{1}$ Patients with NF1 have an increased risk of breast cancer and other malignancies caused by a mutation in $N F 1{ }^{2}$ Women under 50 years with NF1 have a five-fold increased risk of breast cancer. ${ }^{3}$ The incidence of pheochromocytoma with NF1 has been reported to be $0.1 \%-5.7 \%$; autopsy studies find a prevalence up to $13 \% .{ }^{4}$ However, the coexistence of pheochromocytoma and breast cancer in the same NF1 patient is extremely rare. One case has been reported in Turkey, ${ }^{5}$ and no cases have been reported in Asia. Patients with NF1 have a high risk for developing NF1-related tumors. Therefore, a careful workup is necessary in NF1 patients to identify sporadic malignancies.

\section{CONFLICT OF INTEREST STATEMENT}

None declared.

\section{REFERENCES}

1. Uusitalo E, Leppävirta J, Koffert A, Suominen S, Vahtera J, Vahlberg $\mathrm{T}$, et al. Incidence and mortality of neurofibromatosis: a total pop-

\section{Corresponding Author:}

Tae Yang Yu

Division of Endocrinology and Metabolism, Wonkwang University Hospital, 895 muwang-ro, Iksan 54538, Korea Tel: +82-63-859-2670, Fax: +82-63-855-2025, E-mail: yutaeyang@gmail.com

\section{Article History:}

Received November 28, 2019 Revised December 31, 2019 Accepted January 14, 2020 

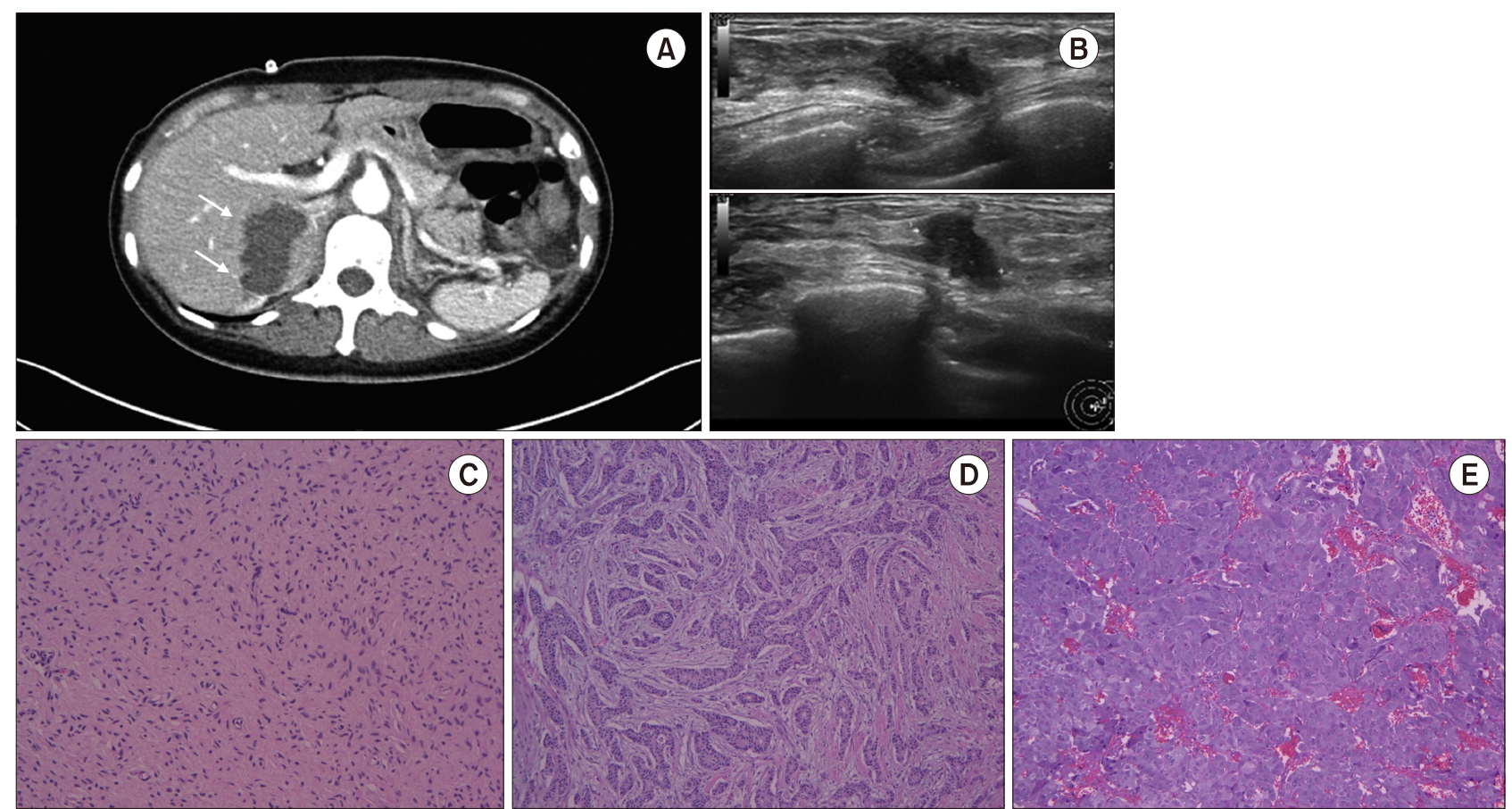

FiG. 2. (A) Abdominal computed tomography showing a 6-cm oval-shaped well-defined mass in the right adrenal gland (arrowed). (B) Breast ultrasonography showing an irregularly spiculated low echoic mass in the left breast. (C) Histopathological finding of neurofibroma of right breast showing bundle of wavy spindle cells with thin oblong nuclei surrounded by collagen (H\&E, $\times 200$ ). (D) Histopathological finding of left breast cancer showing invasive ductal carcinoma with moderately differentiated tumor (H\&E, $\times 100)$. (E) Histopathological finding of pheochromocytoma showing nests of cells (zellballen pattern) surrounded by fibrovascular stroma $(\mathrm{H} \& \mathrm{E}, \times 200)$.

ulation study in Finland. J Invest Dermatol 2015;135:904-6.

2. Viskochil D, Buchberg AM, Xu G, Cawthon RM, Stevens J, Wolff RK, et al. Deletions and a translocation interrupt a cloned gene at the neurofibromatosis type 1 locus. Cell 1990;62:187-92.

3. Suarez-Kelly LP, Yu L, Kline D, Schneider EB, Agnese DM, Carson WE. Increased breast cancer risk in women with neurofibromatosis type 1: a meta-analysis and systematic review of the literature. Hered Cancer Clin Pract 2019;17:12.
4. Walther MM, Herring J, Enquist E, Keiser HR, Linehan WM. von Recklinghausen's disease and pheochromocytomas. J Urol 1999; 162:1582-6.

5. Demirpence MM, Bahceci M, Dolek D, Salgur F, Gorgel A, Tutuncuoglu P. A very rare association; coexistence of breast cancer, pheochromocytoma and neurofibromatosis type 1 in a female patient. Int J Case Rep Med 2013;2013:511990. 